\title{
Efeitos da administração exógena de melatonina sobre o fígado da prole de ratas Wistar submetidas à corticoterapia durante a prenhez
}

\author{
[Effects of exogenous administration of melatonin on the liver of the offspring of Wistar rats \\ submitted to corticotherapy during pregnancy]
}

\section{"Artigo Científico/Scientific Article"}

\author{
Carolline Guimarães D'assunção*, Solange Bezerra da Silva, Cintia Giselle Martins Ferreira, \\ Yuri Mateus Lima de Albuquerque, Rebeka da Costa Alves, Aline Ferreira da Silva Mariano, \\ Álvaro Aguiar Coelho Teixeira, Valéria Wanderley Teixeira
}

Universidade Federal Rural de Pernambuco, Recife-PE, Brasil.

*Autor para correspondência/Corresponding author: E-mail: carolli_15@hotmail.com

\begin{abstract}
Resumo
A dexametasona vem sendo amplamente utilizada em casos de gestação com risco de prematuridade. Entretanto, doses suprafisiológicas podem acarretar complicações e afetar a embriogênese. A melatonina, por sua vez, apresenta efeitos antagônicos aos glicocorticoides. Assim, avaliou-se a ação da dexametasona administrada durante o período gestacional, e a influência da melatonina sobre os efeitos decorrentes da corticoterapia. Foram utilizadas 20 ratas, divididas em 4 grupos: I - ratas prenhes que receberam solução placebo; II - ratas prenhes que receberam dexametasona $(0,8 \mathrm{mg} / \mathrm{kg})$; III - ratas prenhes tratadas com melatonina $(0,5 \mathrm{mg} / \mathrm{kg})$ e IV - ratas prenhes que receberam dexametasona e foram tratadas com melatonina. As amostras foram obtidas da prole com 10, 15 e 20 dias de vida pós-natal. Os resultados mostraram que a dexametasona, administrada a partir do $10^{\circ}$ dia do período gestacional, promoveu uma maior taxa de mortalidade, redução acentuada no ganho de peso desses animais, bem como alterações hepáticas histopatológicas e morfométricas, como esteatose, necrose, vacuolização celular, além de diminuição nos grânulos de glicogênio, carboidratos totais e aumento das fibras colágenas teciduais. Entretanto, os animais do grupo IV, apresentaram alterações mais atenuadas, com parâmetros semelhantes aos animais do grupo controle. Assim, conclui-se que a administração da melatonina exógena pode proteger o fígado dos animais ou atenuar alguns efeitos decorrentes da corticoterapia.
\end{abstract}

Palavras-chave: carboidratos; fígado; filhotes; glicocorticoide.

\begin{abstract}
Dexamethasone has been widely used in cases of pregnancy with risk of prematurity. However, supraphysiological doses can cause complications and affect embryogenesis. Melatonin, in turn, has antagonistic effects to glucocorticoids. Thus, the action of dexamethasone administered during the gestational period, the action of dexamethasone on the offspring of treated rats, and the influence of melatonin on the effects resulting from corticotherapy were evaluated. Twenty rats were used, divided into 4 groups: Pregnant rats that received placebo solution; II- pregnant rats that received dexamethasone $(0.8 \mathrm{mg} / \mathrm{kg})$; III- pregnant rats treated with melatonin $(0.5 \mathrm{mg} / \mathrm{kg})$ and $\mathrm{IV}$ - pregnant rats that received dexamethasone and were treated with melatonin. The samples were obtained from the offspring at 10, 15 and 20 days of postnatal life. The results showed that dexamethasone, administered from the 10th day of the gestational period in the middle third of pregnancy, caused a higher mortality rate, marked reduction in the weight gain of these animals, as well as histological and morphometric liver alterations, such as fatty steatosis, necrosis, cell vacuolization, in addition to decreased glycogen granules, total carbohydrates, and increased tissue collagen fibers. However, animals in group IV showed more attenuated changes, with parameters similar to animals in the control group. Thus, it is concluded that the administration of exogenous melatonin can protect the liver of animals to reverse or mitigate some effects resulting from corticotherapy.
\end{abstract}

Keywords: glucocorticoids; liver; carbohydrates; pups. 


\section{Introdução}

Os glicocorticoides constituem uma classe de fármacos com características anti-inflamatórias e imunossupressoras (Buttgereit et al., 2017). Dentre os glicocorticoides, a dexametasona se destaca por sua maior atividade farmacológica (em comparação com o cortisol e corticosterona), por apresentar alta afinidade por receptores de membranas, auxiliar no metabolismo do cálcio, reduzindo assim retenção de líquido e formação de edemas, além de possuir uma extensa meia-vida (Bavaresco et al., 2005).

Em função de seus efeitos benéficos, a dexametasona vem sendo comumente empregada em casos de gestantes que apresentam risco de partos prematuros (Bruder et al., 2004), pois acelera o desenvolvimento de certos tecidos e órgãos do feto, possibilitando maior probabilidade de sobrevivência do neonato e redução do tempo na incubadora (Locatelli et al., 2010). Vários estudos, entretanto, demonstraram que a administração deste glicocorticoide, em períodos pré-natais, acarreta para o feto uma série de efeitos deletérios (Lee et al., 2012) em alguns órgãos como o pâncreas, fígado, e rins que apresentaram alterações morfofuncionais atribuídas a corticoterapia (Bruder et al., 2004).

A melatonina, por sua vez, pode proporcionar uma redução nas reações indesejadas ocorridas durante o tratamento com a dexametasona. Em estudos utilizando ratas fêmeas jovens, a administração da melatonina, como coadjuvante, preveniu os efeitos prejudiciais causados por este glicocorticoide, tais como diminuição do ganho de peso corporal, atrofia do timo e das adrenais, glicosúria e elevação dos níveis de açúcar, triglicerídeos e colesterol no sangue (Aoyama et al., 1986).

Em mamíferos, a melatonina é um hormônio produzido e secretado pela glândula pineal, sendo um componente importante no mecanismo fotoperiódico, atuando sobre uma variedade de funções neuroendócrinas e fisiológicas, incluindo as funções reprodutivas (Li e Zhou, 2015). Vários estudos demonstraram que o nível de melatonina plasmática aumenta durante a gravidez, atingindo valores elevados no final desse período, sugerindo que este hormônio desempenha um papel importante na manutenção da gestação (Tamura et al., 2008). Além disso, apresenta propriedades imunomodulatórias, atuando tanto na imunidade inata quanto na adquirida (Berger, 2008), desempenhando, também, um papel importante no fígado, regulando vários processos fisiológicos, agindo como um antioxidante e eliminador de radicais livres (Hermoso et al., 2016), podendo até inibir o crescimento de carcinomas hepáticos (Carrillo-Vico et al., 2005).

Assim, faz-se necessário avaliar os efeitos do uso da dexametasona durante o período gestacional sobre a morfofisiologia hepática dos neonatos e verificar como a administração da melatonina exógena influenciaria nesse processo.

\section{Material e Métodos}

Foram utilizadas 20 ratas albinas (Rattus norvegicus albinus), da linhagem Wistar, com 90 dias de idade, virgens e pesando $200 \mathrm{~g} \pm 30 \mathrm{~g}$, procedentes do Biotério do Departamento de Morfologia e Fisiologia Animal-DMFA, da Universidade Federal Rural de PernambucoUFRPE. As fêmeas foram mantidas em gaiolas com alimentação e água 'ad libitum', a uma temperatura de $22^{\circ} \mathrm{C}$, e iluminação artificial que estabeleceu um fotoperíodo de $12 \mathrm{~h}$ claro/12h escuro, considerando o período de luz das 6:00 às 18:00h.

Posteriormente à confirmação do acasalamento, as fêmeas foram separadas em quatro grupos, aleatoriamente, cada um contendo cinco animais: Grupo I- ratas prenhes que receberam com solução salina e etanol (placebo) a partir do $10^{\circ}$ dia de prenhez até o nascimento dos filhotes. Grupo II- ratas prenhes que receberam dexametasona a partir do $10^{\circ}$ dia de prenhez até o nascimento dos filhotes. Grupo III- ratas prenhes tratadas com melatonina a partir do $10^{\circ}$ dia de prenhez até o nascimento dos filhotes. Grupo IVratas prenhes que receberam dexametasona e foram tratadas com melatonina a partir do $10^{\circ}$ dia de prenhez até o nascimento dos filhotes. A duração do período gestacional dos animais corresponde a aproximadamente 21 dias, logo as matrizes receberam 10 dias de administração dos compostos, solução placebo, dexametasona e melatonina.

A dexametasona utilizada foi a formulação comercial Decadron (fosfato dissódico de dexametasona) administrada por via intraperitoneal nas ratas dos grupos II e IV, na dose de $0,8 \mathrm{mg} / \mathrm{kg}$ (Vilaça-Junior et al., 2012). A administração foi realizada no horário entre 17:00 e 18:00 h, a partir do décimo dia de gestação até o nascimento dos filhotes, com redução progressiva da dose em $10 \%$ até a obtenção da dose zero no último dia. 
O tratamento com melatonina foi realizado nas ratas dos grupos III e IV de acordo com o protocolo estabelecido por Kim et al. (1998). A dose de melatonina (Sigma Chemical Co., St. Louis, Mo., USA) administrada foi de $0,5 \mathrm{mg} / \mathrm{kg}$.

Os filhotes foram submetidos aos procedimentos de eutanásia após os períodos experimentais, com 10, 15 e 20 dias de vida pósnatal. Para tanto, foram anestesiados com hidrocloridrato de cetamina $(80 \mathrm{mg} / \mathrm{kg})$ e xilazina $(20 \mathrm{mg} / \mathrm{kg})$, por via intramuscular. Em seguida foi realizada punção cardíaca e coletado $1 \mathrm{~mL}$ de sangue por animal que foi então armazenado em microtubo contendo EDTA (Ethylenediamine tetraacetic acid $)(15 \mu \mathrm{l})$ à temperatura ambiente.

Para análise de carboidratos totais as amostras de plasma foram submetidas à desproteinização, realizada com ácido tricloroacético a 5\% (TCA 5\%) numa proporção de 1:10. A solução foi então centrifugada e $o$ sobrenadante mantido à temperatura de $4^{\circ} \mathrm{C}$. Para a preparação da curva de calibração foi utilizada uma solução estoque de glicose em água destilada na concentração $1 \mathrm{~g} / \mathrm{L}$. As amostras e padrões foram submetidos à leitura do comprimento de onda de $620 \mathrm{~nm}$ em leitora de microplaca (Anthos 2010 Microplate Absorbance Reader, Biochrom Ltd, Cambridge, UK) seguindo a metodologia de Laurentini e Edwards (2003).

Os fígados dos animais para análise histopatológica e histoquímica foram coletados e fixados em formol tamponado à $10 \%$ por $24 \mathrm{~h}$. Os órgãos foram incluídos em parafina, para obtenção dos cortes histológicos, utilizando-se um micrótomo. Estes foram então corados pela Hematoxilina-Eosina (HE), pelo ácido Periódico de Schiff (PAS) e pelo Picro-Sirius (PS). A quantificação em pixels dos grânulos de glicogênio e das fibras colágenas foi realizada utilizando o programa GIMP. 2.8.

$\mathrm{O}$ estudo morfométrico do fígado foi realizado segundo a metodologia descrita por Engelman et al. (2001). Foi determinada, por métodos estereológicos, a proporção entre o parênquima não lobular e lobular do órgão, utilizando uma gratícula com 100 pontos-teste. A contagem foi realizada em cinco lâminas, onde foram contados 10 campos, utilizando-se a objetiva de 40x, totalizando 5.000 pontos por grupo.

Os dados obtidos foram submetidos ao teste paramétrico Anova One-way, onde as médias obtidas foram comparadas pelo post-hoc de Tukey.

\section{Resultados}

Estatisticamente verificou-se uma redução significativa no peso da prole dos grupos que receberam dexametasona (GII e GIV), entretanto os animais que receberam apenas a melatonina exógena apresentaram um ganho de peso, semelhante ao do grupo controle, na fase de desmame, que corresponde ao $20^{\circ}$ dia de vida pósnatal (Tabela 1).

Tabela 1. Média \pm desvio padrão do peso $(\mathrm{g})$ dos neonatos de ratas submetidas ou não à corticoterapia e tratadas ou não com melatonina exógena.

\begin{tabular}{cccccc}
\hline Dias de vida & GI & GII & GIII & GIV & P \\
\hline 1 & $6,109 \pm 0,37 \mathrm{a}$ & $3,74 \pm 0,63 \mathrm{~b}$ & $6,57 \pm 0,35 \mathrm{a}$ & $5,17 \pm 0,59 \mathrm{~b}$ & 0,0002 \\
5 & $11,58 \pm 0,65 \mathrm{a}$ & $8,374 \pm 0,64 \mathrm{~b}$ & $11,72 \pm 0,79 \mathrm{a}$ & $9,084 \pm 0,69 \mathrm{~b}$ & 0,001 \\
10 & $17,82 \pm 0,56 \mathrm{a}$ & $14,56 \pm 2,48 \mathrm{~b}$ & $19,81 \pm 1,25 \mathrm{c}$ & $15,49 \pm 1,04 \mathrm{~b}$ & 0,0023 \\
15 & $27,36 \pm 1,8 \mathrm{a}$ & $23,51 \pm 1,02 \mathrm{~b}$ & $29,9 \pm 0,98 \mathrm{c}$ & $24,2 \pm 1,23 \mathrm{~b}$ & 0,0006 \\
20 & $47,53 \pm 1,04 \mathrm{a}$ & $38,51 \pm 1,89 \mathrm{~b}$ & $46,6 \pm 1,22 \mathrm{a}$ & $40,89 \pm 1,56 \mathrm{~b}$ & 0,003 \\
\hline
\end{tabular}

${ }^{1}$ Médias seguidas pela mesma letra não diferem significativamente entre si pelo teste Anova one-way com post hoc de Tukey (p>0,05). GI- Placebo; GII- Dexametasona; GIII- Melatonina e GIV- Dexametasona+Melatonina.

Já com relação ao comprimento dos neonatos, a prole oriunda das matrizes dos grupos II e IV apresentou uma diminuição característica, entretanto o tratamento com a melatonina exógena foi capaz de promover semelhanças com os valores observados no grupo controle durante 1,5 e 15 dias do desenvolvimento pós-natal, como pode ser observado no grupo IV (Tabela 2).

Com relação à taxa de natalidade, foi possível observar que o grupo que recebeu apenas dexametasona (GII) apresentou uma quantidade menor de neonatos, com elevada taxa de mortalidade, condição essa que não foi observada nos demais grupos experimentais, demonstrado a ação protetora da melatonina (Figura 1).

Com relação aos níveis de carboidratos totais, nos filhotes 10 dias de vida observou-se um aumento significativo no grupo tratado com dexametasona. Também foi observado um aumento no grupo tratado com dexametasona 
associado à melatonina, porém sem diferir dos demais grupos experimentais. Com 15 dias de vida pós-natal, o padrão foi mantido, com níveis elevados no GII, e aos vinte dias de vida não foram observadas variações significativas (Tabela 3).

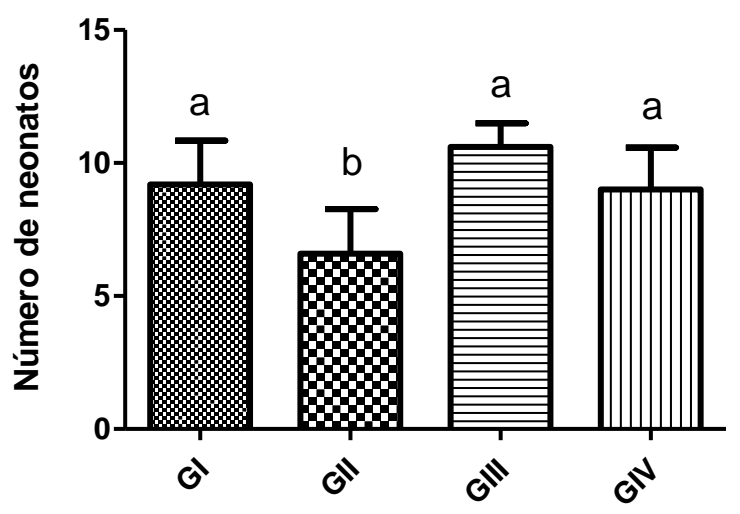

Figura 1. Gráfico do número total de animais nascidos das matrizes dos diferentes grupos experimentais. GI - Placebo; GII Dexametasona; GIII - Melatonina e GIV Dexametasona + Melatonina.
Histologicamente os fígados da prole do grupo I, tanto com 10, 15 e 20 dias pós-natal, apresentaram externamente uma delgada cápsula composta de tecido conjuntivo fibroso, um parênquima bem desenvolvido com uma malha vascular com veias de vários calibres, como as veias centro lobulares e veias portais. Os hepatócitos dispuseram-se em placas, direcionadas da periferia do lóbulo para o seu centro, em torno da veia centro lobular, margeando os capilares sinusóides (Figura 2A). Os mesmos aspectos foram observados no fígado de toda prole do grupo III, (Figura 2B). Entretanto, em todos os filhotes do grupo II foi verificada presença de vacuolização celular difusa caracterizando um quadro de esteatose hepática intensa, assim como necrose dos hepatócitos (Figura 2C). Os animais do grupo IV também apresentaram um quadro de esteatose e necrose, entretanto de forma moderada comparando-se com os animais do grupo II (Figura 2D).

Tabela 2. Média \pm desvio padrão do comprimento $(\mathrm{cm})$ dos neonatos de ratas submetidas ou não à corticoterapia e tratadas ou não com melatonina exógena.

\begin{tabular}{cccccc}
\hline Dias de Vida & GI & GII & GIII & GIV & P \\
\hline 1 & $6,416 \pm 0,15 \mathrm{a}$ & $5,432 \pm 0,23 \mathrm{~b}$ & $6,214 \pm 1,1 \mathrm{a}$ & $6,262 \pm 0,45 \mathrm{a}$ & 0,003 \\
5 & $9,2 \pm 1,1 \mathrm{a}$ & $7,446 \pm 1,27 \mathrm{~b}$ & $8,778 \pm 0,33 \mathrm{a}$ & $7,884 \pm 1,34 \mathrm{a}$ & 0,001 \\
10 & $11,95 \pm 1,36 \mathrm{a}$ & $9,606 \pm 0,78 \mathrm{~b}$ & $12,14 \pm 1,78 \mathrm{a}$ & $9,436 \pm 1,5 \mathrm{~b}$ & 0,002 \\
15 & $14,47 \pm 0,23 \mathrm{a}$ & $12,47 \pm 0,96 \mathrm{~b}$ & $15,09 \pm 1,90 \mathrm{a}$ & $13,1 \pm 1,24 \mathrm{a}$ & 0,005 \\
20 & $18,92 \pm 1,44 \mathrm{a}$ & $16,16 \pm 1,43 \mathrm{~b}$ & $19,45 \pm 1,65 \mathrm{a}$ & $16,03 \pm 1,85 \mathrm{~b}$ & 0,004 \\
\hline
\end{tabular}

${ }^{1}$ Médias seguidas pela mesma letra não diferem significativamente entre si pelo teste Anova one-way com post hoc de Tukey (p>0,05). GI- Placebo; GII- Dexametasona; GIII- Melatonina e GIV- Dexametasona+Melatonina.

Tabela 3. Média \pm desvio padrão dos níveis séricos de carboidratos toais $(\mathrm{mg} / \mathrm{dL})$ dos neonatos de ratas submetidas ou não à corticoterapia e tratadas ou não com melatonina exógena.

\begin{tabular}{cccccc}
\hline Grupos/Dias & I & II & III & IV & P \\
\hline 10 & $461,20 \pm 28,24 \mathrm{a}$ & $580,09 \pm 32,10 \mathrm{~b}$ & $458,15 \pm 39,03 \mathrm{a}$ & $508,08 \pm 30,17 \mathrm{a}$ & 0,0343 \\
15 & $450,08 \pm 39,83 \mathrm{a}$ & $638,25 \pm 46,82 \mathrm{~b}$ & $487,52 \pm 37,42 \mathrm{a}$ & $510,12 \pm 35,01 \mathrm{a}$ & 0,007 \\
20 & $470,80 \pm 24,09 \mathrm{a}$ & $440,92 \pm 47,78 \mathrm{a}$ & $423,63 \pm 41,63 \mathrm{a}$ & $497,52 \pm 42,23 \mathrm{a}$ & 0,4090
\end{tabular}

${ }^{1}$ Médias seguidas pela mesma letra não diferem significativamente entre si pelo teste Anova one-way e post hoc de Tukey (p>0,05). GI - Placebo; GII - Dexametasona; GIII - Melatonina e GIV - Dexametasona + Melatonina.

Morfologicamente foi observada uma redução no parênquima lobular (PL) dos animais do grupo II. Com 10 dias de vida essa diminuição foi acentuada diferindo significativamente de todos os demais grupos experimentais. Já com 15 e 20 dias, essa diminuição também foi observada nos animais que receberam melatonina (grupo IV). Já em relação ao parênquima não lobular (PNL), foram observadas poucas diferenças significativas entre os grupos, com um aumento no grupo III com 10 dias de vida pós-natal e uma redução apenas com 15 dias de vida pós-natal. Aos 20 dias diferenças significativas não foram observadas. (Tabela 4). 
Tabela 4. Média \pm desvio padrão da análise morfométrica do fígado dos neonatos de ratas submetidas ou não à corticoterapia e tratadas ou não com melatonina exógena com as diferenças entre o parênquima lobular (PL) e parênquima não lobular (PNL).

\begin{tabular}{|c|c|c|c|c|c|}
\hline Grupos/Dias & GI & GII & GIII & GIV & $\mathbf{P}$ \\
\hline \multicolumn{6}{|c|}{10 Dias de Vida Pós- Natal } \\
\hline PL $(\%)$ & $73,6 \pm 18,4 a$ & $41,3 \pm 11,4 b$ & $75,2 \pm 7,7 \mathrm{a}$ & $76,2 \pm 17,6 a$ & 0,0001 \\
\hline PNL $(\%)$ & $10,9 \pm 1,5 \mathrm{a}$ & $9,8 \pm 1,2 \mathrm{a}$ & $25,1 \pm 1,7 b$ & $10,7 \pm 1,1 \mathrm{a}$ & 0,041 \\
\hline \multicolumn{6}{|c|}{15 Dias de Vida Pós-Natal } \\
\hline PL (\%) & $69,0 \pm 4,6 a$ & $36,6 \pm 1,4 b$ & $71,9 \pm 4,8 \mathrm{a}$ & $31,6 \pm 1,9 b$ & 0,0007 \\
\hline PNL (\%) & $14,5 \pm 1,2 \mathrm{a}$ & $13,0 \pm 1,1 \mathrm{ab}$ & $12,0 \pm 1,5 \mathrm{ab}$ & $8,9 \pm 0,9 b$ & 0,02 \\
\hline \multicolumn{6}{|c|}{20 Dias de Vida Pós-Natal } \\
\hline PL $(\%)$ & $59,4 \pm 5,3 a$ & $22,5 \pm 2,0 b$ & $52,0 \pm 2,2 \mathrm{a}$ & $28,9 \pm 2,2 b$ & 0,0046 \\
\hline $\operatorname{PNL}(\%)$ & $10,9 \pm 0,9 \mathrm{a}$ & $10,6 \pm 1,0 \mathrm{a}$ & $12,7 \pm 1,6 \mathrm{a}$ & $11,7 \pm 1,6 \mathrm{a}$ & 0,22 \\
\hline
\end{tabular}

${ }^{1}$ Médias seguidas pela mesma letra não diferem significativamente entre si pelo teste Anova one-way, com post hoc de Tukey ( $\left.\mathrm{p}>0,05\right)$. GI - Placebo; GII - Dexametasona; GIII - Melatonina e GIV - Dexametasona + Melatonina.
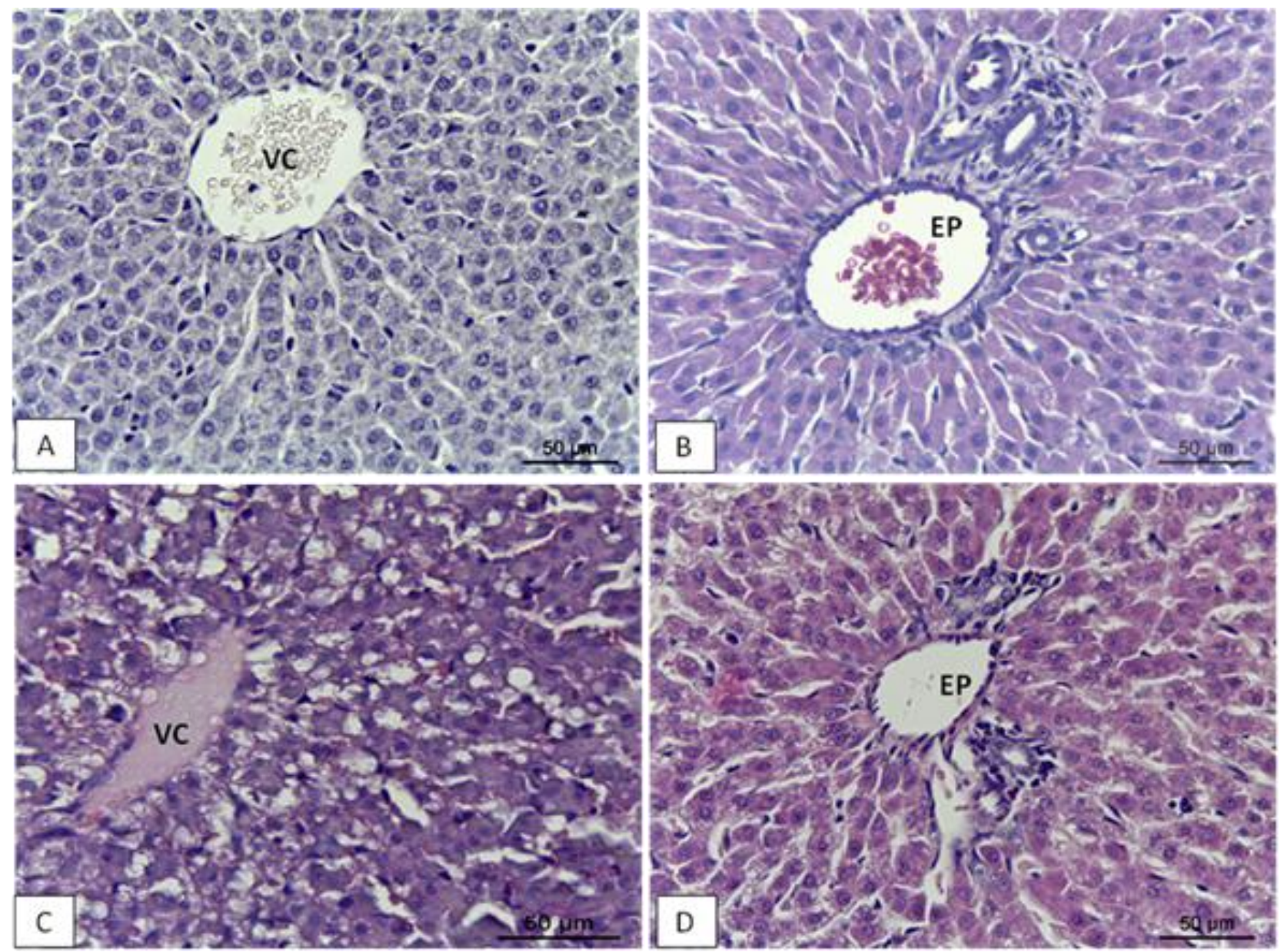

Figura 2. Fotomicrografia do fígado dos neonatos dos grupos experimentais: A) grupo I (fígado de animais com 15 dias de vida pós-natal) e B) grupo III (fígado de animais com 15 dias de vida pós-natal). Observar parênquima hepático preservado, com hepatócitos (seta) convergindo para veia centro-lobular (VC) e a presença do espaço porta (EP). C) grupo II (fígado de animais com 15 dias de vida pós-natal). Presença de degeneração macro e microvacuolar (representada pela ponta de seta) e necrose (asterisco). D) grupo IV (fígado de animais com 15 dias de vida pós-natal). Presença de degeneração microvacuolar discreta. Coloração HE. Aumento 400x.

A análise histoquímica do fígado pelo PAS, para identificação dos grânulos de glicogênio, apresentou reação de intensidade variada, sendo mais intensa nos filhotes do grupo II e IV com 10 dias de vida pós-natal (Figura 3A). Com 15 dias, ocorreu um aumento significativo apenas nos animais do grupo II (Figura 3B). Com 20 dias, apenas os animais do grupo IV, apresentaram 
redução diferindo significativamente do grupo controle enquanto que os demais grupos não diferiram entre si (Figura 3C).

A contagem das fibras colágenas demonstrou que os animais do grupo II

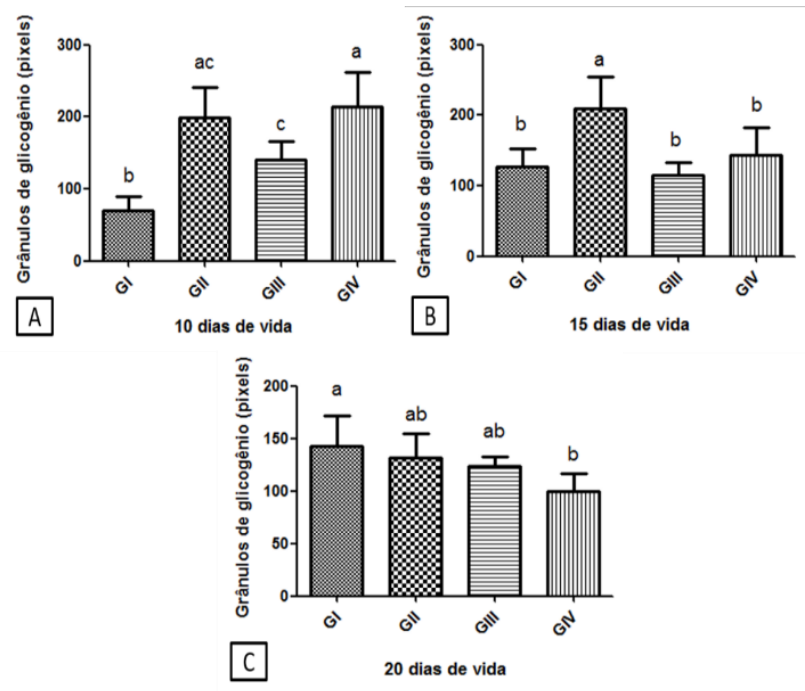

Figura 3. Gráfico da quantificação de glicogênio (em pixels) no fígado da prole dos animais dos grupos experimentais. A) Filhotes com 10 dias de vida pós-natal. B) Filhotes com 15 dias de vida pós-natal. C) Filhotes com 20 dias de vida pós-natal. GI - Placebo; GII Dexametasona; GIII - Melatonina e GIV Dexametasona + Melatonina.

\section{Discussão}

Em estudo realizado com diferentes espécies, incluindo humanos e roedores, observouse que o tratamento pré-natal com glicocorticoide reduz o peso dos neonatos, e promove alterações no eixo hipotálamo-pituitário-adrenal, encontradas na vida pós-natal da prole (Seckl, 2004). Além disso, os efeitos dos glicocorticoides exógenos sobre o peso e tamanho/comprimento fetal são maiores quando administrados durante períodos de crescimento rápido, tipicamente nos últimos estágios da gravidez (Nyirenda et al., 1998), como ocorreu no presente estudo, com a administração da dexametasona a partir do terço médio da gestação.

Como nos trabalhos de Seckl (2004) e Nyirenda et al. (1998), nossos achados mostraram que também houve uma redução no peso e comprimento da prole oriunda de matrizes que receberam dexametasona associada à melatonina. Este hormônio vem sendo relacionado com a habilidade de aumentar a capacidade de termogênese, convertendo a energia extra em calor, levando a eliminação de energia com um retardamento no ganho de peso corporal (Tan et al., 2011). Essa capacidade da melatonina em relação à apresentaram uma maior quantidade dessas fibras nos tempos de 10 e 15 dias de vida pós-natal quando comparado com os demais grupos, já com 20 dias de vida, não foram evidenciadas diferenças significativas entre os grupos analisados (Figura 4).

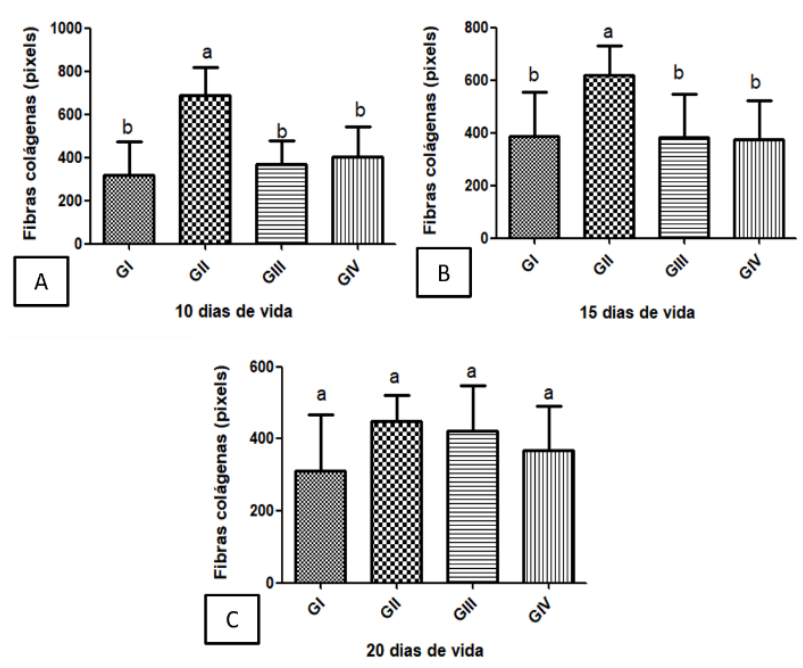

Figura 4. Gráfico da quantificação de fibras colágenas (em pixels) no fígado da prole dos animais dos grupos experimentais. A) Filhotes com 10 dias de vida pós-natal. B) Filhotes com 15 dias de vida pós-natal. C) Filhotes com 20 dias de vida pós-natal. GI - Placebo; GII Dexametasona; GIII - Melatonina e GIV Dexametasona + Melatonina.

diminuição do peso pode ter afetado os neonatos quando administrada juntamente com a dexametasona, potencializando seus efeitos, uma vez que na prole do grupo apenas tratado com melatonina essa redução não foi observada.

Doses elevadas de glicocorticoides também podem levar ao aborto (Austad et al., 1976), supõese que os glicocorticoides exercem uma forte atividade de feedback negativo sobre a secreção de ACTH (hormônio adrenocorticotrófico) e gonadotrofinas hipofisárias, levando a uma incapacidade de manter a prenhez (Feldman e Nelson, 1991). Diversos trabalhos demonstraram que a aplicação da dexametasona, mesmo em doses pequenas, variando de 0,2 a $0,5 \mathrm{mg} / \mathrm{kg}$, no período gestacional promoveu retenção placentária, nascimento de prole morta ou extremamente fraca, (Bravo et al., 1996; Feldman e Nelson, 1991; Shille, 1982) como no nosso estudo, onde a dosagem de $0,8 \mathrm{mg} / \mathrm{kg}$ acarretou em um número menor de neonatos dos grupos tratados com dexametasona. Já a administração de melatonina foi capaz de regularizar essa taxa, com número de neonatos semelhantes ao do grupo controle. Dair et al. (2008) que realizaram estudo com ratas prenhes, 
onde ocorreu à remoção da glândula pineal, observaram que os níveis baixos de melatonina promoveram diminuição da implantação embrionária, sugerindo a atuação deste hormônio sobre algumas características morfofuncionais do endométrio estritamente relacionadas com a implantação do embrião e consequentemente com o sucesso reprodutivo.

Trabalhos realizados utilizando-se a dexametasona sugerem que esse GC promova uma combinação de elevada síntese de triacilgliceróis e uma diminuição na lipólise, resultando no acúmulo de lipídio hepático (Dolinsky et al., 2004). Esses trabalhos corroboram nossos achados, onde a administração da dexametasona promoveu um quadro de esteatose nos neonatos oriundos de matrizes tratadas com este glicocorticoide a partir do terço médio da gestação, período este em que se sabe que a ação da $11 \beta$-HSD2 possui menor bioatividade, fazendo com que o feto tenha contato elevado com os glicocorticoides maternos (Reynolds, 2013).

Além disso, sabe-se que os glicocorticoides induzem a produção de ROS (espécies reativas de oxigênio) e que nesta condição, há o estabelecimento de esteatose hepática, bem como morte celular, observando-se áreas necrosadas no tecido (You et al., 2009), levando a uma diminuição do parênquima hepático, como observado na análise morfométrica do presente estudo. A redução do parênquima leva consequentemente à produção de tecido fibroso (cicatricial), aumentando a quantidade de fibras colágenas teciduais, como observado no grupo II.

A melatonina parece ter atenuado os efeitos ocasionados pela administração da dexametasona, talvez pela sua ação anti-oxidante e eliminadora de radicais livres, possuindo ação direta em tecido hepático, através de receptores específicos encontrados nas membranas dos hepatócitos (ElSokkary et al., 2003).

Com relação aos níveis de carboidratos, sob a ação da dexametasona o fígado aumenta a produção de glicose hepática pela inversão da via glicolítica e por induzir formação de glicogênio a partir de substratos resultantes de processos de gliconeogênese (Santos et al., 2007), elevando sua concentração.

\section{Conclusão}

A administração de melatonina foi capaz de atenuar os efeitos deletérios oriundos da corticoterapia durante o período gestacional, protegendo os filhotes, sendo, portanto, considerada uma alternativa terapêutica eficaz.

\section{Conflito de interesse}

Os autores declaram não existir conflito de interesse.

\section{Comitê de Ética}

$\mathrm{O}$ projeto de pesquisa foi aprovado no comitê de ética da Universidade Federal Rural de Pernambuco sob o número 23082.017195/2010.

\section{Referências}

Aoyama, H.; Mori, W.; Mori, N. Antiglucocorticoid effects of melatonin in young rats. Acta Pathologica Japonica, 36(3): 423428, 1986.

Austad, R.; Lunde, A.; Sjaastad, O. Peripherical plasma levels of estradiol-17í3 and progesterone in the bitch during the oestrus cycle in normal pregnancy and after dexamethasone treatment. Journal Reproduction Fertility, 46(1): 119-136, 1976.

Bavaresco, L.; Bernardi, A.; Battastini, A.M.O. Glicocorticoides: usos clássicos e emprego no tratamento do câncer. Infarma, 17(7/9): 58-60, 2005.

Berger, J. A two-clock model of circadian timing in the immune system of mammals. PathologieBiologie, 56(5): 286- 291, 2008.

Bravo, P.W.; Bazan, P.J.; Villata, P.R. Induction of parturition in alpacas and subsequent survival of neonates. Journal of the American Veterinary Medical Association, 209(10): 1760-1762, 1996.

Bruder, E.D.; Lee, P.C.; Raff, H. Metabolic consequences of hypoxia from birth and dexamethasone treatment in the neonatal rat: comprehensive hepatic lipid and fatty acid profiling. Endocrinology, 145(11): 5364-5372, 2004.

Buttgereit, F.; Bijlsma, J.W.J.; Strehl, C. Will we ever have better glucocorticoids? Clinical Immunology, 186: 64-66, 2017.

Carrilo-Vico, A.; Calvo, J.R.; Abreu, P.; Lardone, P.J.; Garcia-Mauriño, S.; Choi, W.S.; Cho, G. J.; Won, C. K.; Koh, P.O. Expression of melatonin growth factors mRNA in the rat placenta during mid-late pregnancy. Journal of veterinary science, 6(3): 179-183, 2005.

Dair, E.L.; Simões, R.S.; Simões, M.J.; Romeu, L.R.; Oliveira-Filho, R.M.; Haidar, M.A.; Baracat, E.C.; Soares, J.M.Jr. Effects of 
melatonin on the endometrial morphology and embryo implantation in rats. Fertility and Sterility, 89(5): 1299-1305, 2008.

Dolinsky, V.W.; Douglas, D.N.; Lehner, R; Vance, D.E. Regulation of the enzymes of hepatic microsomal triacylglycerol lipolysis and reesterification by theglucocorticoid dexamethasone. Journal of Biochemistry, 378(3): 967-974, 2004.

El-Sokkary, G.H.; Reiter, R.J.; Abdel-Ghaffar, S.K.H. Melatonin supplementation restores cellular proliferation and DNA synthesis in the splenic and thymic lymphocytes of old rats. Neuro Endocrinology Letters, 24(3-4): 215223, 2003.

Engelman, M.F.B.; Neto, J.G.; Andrade, C.H.V.; Hernandez, R.; Goulart, L.B.N.T. Estudo morfométrico do fígado de ratos submetidos a doses supra-fisiológicas de tiroxina. Arquivos Brasileiros de Endocrinolia \& Metabologia, 45(2): 173-179, 2001.

Feldman, E.; Nelson, R. Canine and feline endocrinology and reproduction. Philadelphia: W. B. Saunders, 1991. 629p.

Hermoso, D.A.M.; Shimada, L.B.C.; Gilglioni, E. H.; Constantin, J.; Mito, M.S.; Hermoso, A.P.M.; Iwamoto, E.L.I. Melatonin protects female rats against steatosis and liver oxidative stress induced by oestrogen deficiency. Life Sciences, 157: 178-186, 2016.

Kim, Y.S.; Joo, W.S.; Jin, B.K.; Cho, Y.H.; Baik, H.H.; Park, C.W. Melatonin protects 6-OHDAinduced neuronal death of nigrostriatal dopaminergic system. Neuroreport, 9(10): 2387-2390, 1998.

Laurentini, A.; Edwards, C.A.A. Microtiter modification of the anthrone-sulfuric acid colorimetric assay for glucose-based carbohydrates. Analytical Biochemistry, 315(1): 413-415, 2003.

Locatelli, A.; Ghidini, A.; Incerti, M.; Toso, L.; Plevani, C.; Andreani, M.; Paterlini, G. Gestational age at glucocorticoids administration after premature rupture of membranes and cerebral white matter damage The Journal of Maternal-Fetal \& Neonatal Medicine, 23(6): 511-515, 2010.

Lee, J.Y.; Park, S.J.; Kim, S.H.; Kim, M. H. Prenatal administration of dexamethasone during early pregnancy negatively affects placental development and function in mice. Journal of Animal Science, 90(13): 48464856, 2012.
Li, C.; Zhou, X. Melatonin and male reproduction. Clinica Chimica Acta, 446: 175-180, 2015.

Nyrienda, M.J.; Lindsay, R.S.; Kenyon, C.J.; Burchell, A.; Seckl, J.R. Glucocorticoid exposure in late gestation permanently programs rat hepatic phosphoenolpyruvate carboxykinases and glucocorticoid receptor expression and causes glucose intolerance in adult offspring. Journal of Clinical Investigation, 101(10): 2174-2181, 1998.

Reynolds, R.M. Glucocorticoid excess and the developmental origins of disease: Two decades of testing the hypothesis. Psychoneuroendocrinology, 38(1): 1-11, 2013.

Santos, C.L.; Rafacho, A.; Bosqueiro, J.R. Efeitos da administração da dexametasona in vivo sobre glicemia, insulinemia e substratos circulantes são dependentes de tratamento. Bioscience Journal, 23(3): 101-110, 2007.

Seckl, J.R. Prenatal glucocorticoids and long-term programming. European Journal of Endocrinology, 151(3): U49-U62, 2004.

Shille, V.M. Mismating and termination of pregnancy. Veterinary Clinics of North America: Small Animal Practice, 12(1): 99106, 1982.

Tamura, H.; Nakamura, Y.; Terron, M.P.; Flores, L. J.; Manchester, L.C.; Tan, D.X.; Reiter, R.J. Melatonin and pregnancy in the human. Reproductive Toxicology, 25(3): 291-303, 2008.

Tan, D.X.; Manchester, L.C.; Fuentes-Broto, L.; Paredes, S.D.; Reiter, R.J. Significance and application of melatonin in the regulation of brown adipose tissue metabolism: relation to human obesity. Obesity Reviews: an Official Journal of the International Association For the Study of Obesity 12(3): 167-188, 2011.

Vilaça-Junior, P.E.A.; Soares, A.F.; WanderleyTeixeira, V.; Araújo, A.C.C.; Teixeira, A.A.C. Efeito da administração pré-natal da dexametasona em ratas sobre os perfis glicídicos e hematológicos materno e da prole. Arquivo Brasileiro de Medicina Veterinária e Zootecnia, 64(3): 606-614, 2012.

You, J.M.; Yun, S.J; Nam, K.N.; Kang, C.; Won, R.; Lee, E.H. Mechanism of glucocorticoidinduced oxidative stress in rat hippocampal slice cultures. Canadian Journal of Physiology and Pharmacology, 87(6): 440-7, 2009. 